\title{
An Analysis of Failure of Dynamic Hip Screw with Plate in the Management of Intertrochanteric Fractures
}

\author{
Mohan $\mathrm{N} \mathrm{S}^{1}$, Chandrashekar H S \\ ${ }^{\text {I}}$ (Department of Orthopedics, Sanjay Gandhi Trauma Care Hospital, Bangalore, India) \\ ${ }^{2}$ (Department of Orthopedics, Sanjay Gandhi Trauma Care Hospital, Bangalore)
}

\begin{abstract}
Intertrochanteric femoral fractures are common among older age group and are associated with substantial morbidity and mortality. Open reduction and internal fixation using dynamic hip screw (DHS) device remains the gold standard in the management of these fractures, but the fixation failure rate remains high especially in unstable fractures. This study was conducted on failures of dynamic hip screw fixation in the management of interochanteric femoral fractures between 2009 to 2011.Pre and post operative radiographs were assessed for fracture reduction. Using Evan's classification and Singh's index fractures were categorized and assessed for osteoporosis. Fracture pattern, fracture reduction, implant placement and degree of osteoporosis have been analyzed and shown to affect the rate of implant failure.
\end{abstract}

Keywords: Dynamic hip screw, fracture reduction, interochanteric fracture, implant failure, osteoporosis.

\section{INTRODUCTION}

Intertrochanteric fractures are most frequently operated fracture type and has highest postoperative fatality rate ${ }^{[1]}$. More than $2,00,000$ fractures occur every year and the incidence is expected to double by $2020^{[2]}$. A wide variety of treatment modalities are available for the management of these fractures and many authors have reported excellent results with the use of dynamic hip screw ${ }^{[3]}$. However, the failure rate varies from $4 \%-20 \%$ in the unstable fracture pattern and the factors responsible for treatment failure remains controversial ${ }^{[4]}$. The purpose of this study was to analyze the results of failed DHS cases and predict the postoperative complications using simple radiography. The significance of tip apex distance (TAD), screw placement and degree of osteoporosis have been emphasized in analyzing the failure of dynamic hip screw fixation.

\section{Materials \& Methods}

This retrospective study was conducted in a tertiary care trauma centre on failures of dynamic hip screw fixation. A total of 87 cases (53 males; 34 females), were included in the study group with age group between 60 to 80 years. Patients with acute unilateral, non pathological intertrochanteric fractures were treated by open reduction and internal fixation using dynamic hip screw of $135^{\circ}$ angle. All the fractures were reduced anatomically and fixed rigidly under fluroscopic control. A standard postoperative protocol was maintained which included non weight bearing for 2 months and assisted weight bearing for another 1 month with calcium and vitamin D supplementation. Minimum follow up period was up to 24 months.

In all the cases pre- and postoperative radiographs were taken and assessed for fracture reduction. A good reduction had normal or slightly valgus neck-shaft alignment in Anterio-posterior view or $20^{\circ}$ angulations in the lateral radiograph. Evan's classification ${ }^{[5]}$, was used to classify the fractures as stable and unstable. The other parameters like Singh's index, Tip apex distance, screw placement and barrel size were noted. For the purpose of analysis, post fixation radiographs were assessed to classify fracture fixation as stable and unstable.

Criteria for stable fixation included-

- Maintenance of posterior-medial cortex continuity

- Maintenance of anatomical relationship between the fragments

- Screw placement in the central zone

- Tip apex distance $<25 \mathrm{~mm}$.

Screw placement were classified as central and off central groups based on radiographic division of femoral head into 9 columns in the lateral views.

The above parameters were compared between dynamic hip screw failure cases and patients with uneventful fracture healing. 


\section{Results}

Out of 87 total cases, 80 patients ( 50 males, 30 females) were available for evaluation and 7 of them lost follow up. 56 patients belonged to stable group and 24 were in unstable group. Osteoporosis was noted in 60 cases, out of which 44 cases had stable fixation and 16 cases had unstable fixation. 20 cases had Singh's index more than 3 . Screw was placed centrally in 56 cases and 24 were off the centre. In stable group, failure rate was 3.5\% (2/80) and in unstable group failure rate was 33\% (8/80). Two failed cases of stable fixation had osteoporotic bone (Figure 1).

\section{Discussion}

Dynamic hip screw fixation has gained wide acceptance in the recent years in managing intertrocanteric femoral fractures ${ }^{[6]}$. Numerous classification system have been proposed to classify intertrocanteric fractures which includes Boyd and Griffin's, Evan's, AO system and JC Scott ${ }^{[4]}$. This indicates complexity of the fracture pattern \& still universally accepted classification has not been developed. In 1949, Evan classified these fractures in a simple and easy way into type I (stable fractures) and type II (unstable fractures). In stable fractures, the fracture line runs upwards \& outwards from lesser trochanter and in the unstable fractures, fracture line runs downwards \& outwards from the lesser trochanter ${ }^{[5]}$. In the present study $70 \%$ cases (56/80) had type I fractures and $30 \%$ (24/80) had type II fractures.

Early surgical stabilization of intertrocanteric fractures is important to reduce the complications associated with long term immobilization and to decrease mortality ${ }^{[7]}$. Reverse obliquity intertrochanteric fractures are unstable with unique anatomical and mechanical characteristics. Weight on the fractured limb generates a shearing movement at the fracture side and results in telescoping of the implant, especially in sliding hip screw fixation. These fractures therefore pose a great challenge to both patients and orthopedic surgeons ${ }^{[8]}$. The aim of the surgical treatment of intertrochanteric fracture is to internally fix after stable reduction. The mechanical integrity of the implant construct mainly depends upon the reduction, implant used and the implant position. The surgeon must also be prepared to deal with varus angulation, posterior sag \& malrotation of fragments during the reduction. Varus angulation can be corrected by placing additional traction to dis-engage the fracture fragments. If the reduction is not obtained, lower extremity is abducted.

If posterior sag is present traction is released \& manual correction is done using periosteal; elevator or bone spike. In case of posteriomedial communition, posteriomedial cortex integrity can be obtained by medial displacement osteotomy. But since the advent of Dynamic hip screw anatomical alignment differs from that of anatomical reduction \& its goal is simply to align the head \& neck fragments with the shaft rather than to reduce \& stabilize all the fracture fragments. Dynamic hip screw is used to allow controlled fracture impaction ${ }^{[9]}$. Dynamic hip screw is the gold standard implant for intertrochanteric fracture of the femur, but the implant failure is more in case of unstable fractures (Figure 2). Few studies has shown Dynamic condylar screw is a better implant for the reverse oblique Fractures (Type II) than the dynamic hip screw as the impaction forces will be acting perpendicular to the fracture site ${ }^{[10]}$.

Centrally placed screw is ideal than off centre position to avoid screw cut outs, but the controversy exits in the literature whether to put screw in centre position or posterior-inferior position ${ }^{[1]}$. In the present study 24 cases were in off centre position. Tip apex distance also influences the implant failure. It is the average distance between tip of the screw and medial border of the head of femur ${ }^{[4]}$. Baumgaertner et al ${ }^{[8]}$, devised this concept and showed that cases with TAD $<25 \mathrm{~mm}$ had no failure rates, while TAD $>30 \mathrm{~mm}$ had $27 \%$ implant failure rate. A similar observation was noted in our study, out of 8 implant failure cases $5(62.5 \%)$ of them had TAD $>30 \mathrm{~mm}$.

Many authors have emphasized the usefulness of Singh's index in grading the osteoporosis and have concluded that implant failure is more common in osteoporotic bone ${ }^{[4,6]}$. In our study, osteoporosis was noted in 66 cases and 16 of them had unstable fixation. Size of the barrel is also known to affect the implant failure. When screw of $70 \mathrm{~mm}$ is used, short barrel of $25 \mathrm{~mm}$ is preferred. Short barrels are useful in cases of small femur and when long impaction distance is expected ${ }^{[11]}$.

\section{CONCLUSION}

Dynamic hip screw remains gold standard in the management of intertrochanteric femoral fractures. Reverse oblique fractures are better managed with dynamic condylar screw (Figure 3). The rate of implant failure largely depends on degree of osteoporosis, screw position and tip apex distance. 
VI. Figures

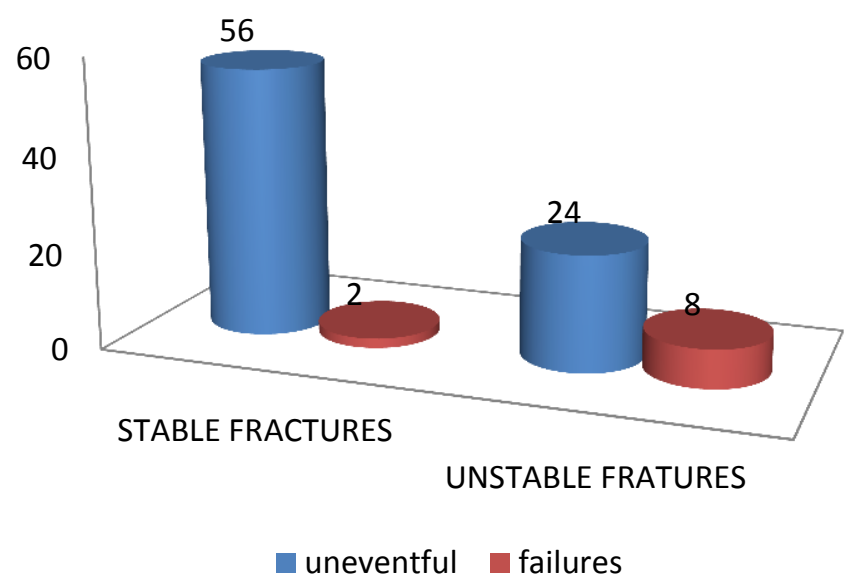

Fig. 1: Graphical representation showing failed DHS cases in stable and unstable fracture fixation groups

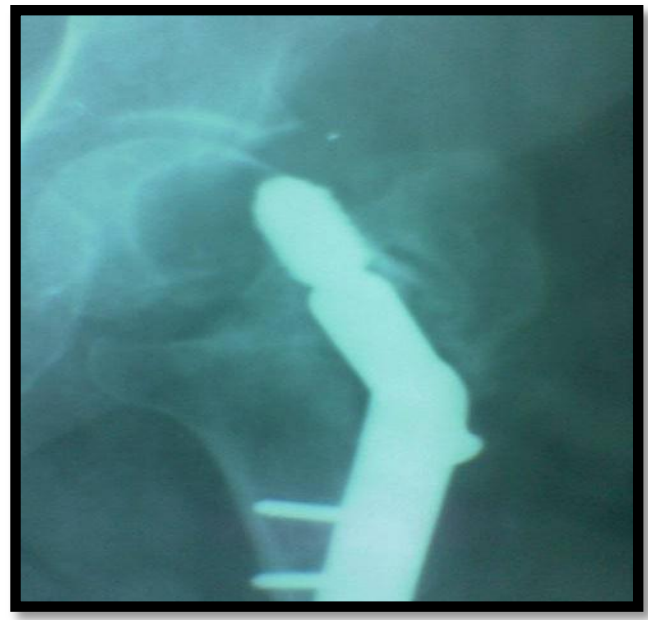

Fig. 2: X ray photograph (AP view) showing DHS placed in off centre position resulting in screw cut out

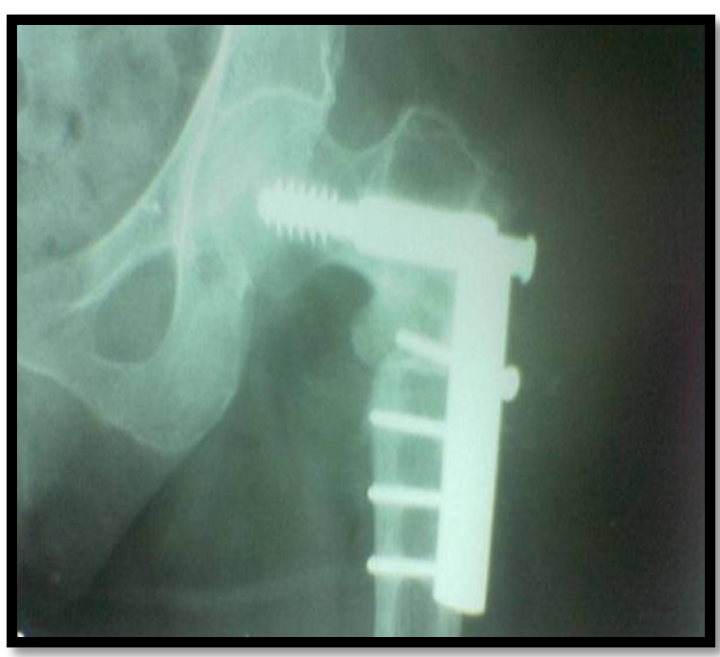

Fig. 3: $\mathrm{X}$ ray photograph (AP view) showing reverse oblique fracture fixed with dynamic condylar screw 


\section{REFERENCES}

[1] Koval KJ, Cantu RV, Intertrochanteric fractures, in Buchloz RW, Heckman JD, Courtbrown CM, Tornetta III P, Mcqueen MM, Ricci WM. (7 $\left.{ }^{\text {th }} \mathrm{Ed}\right)$, Rockwood and Green's Fractures in adults, (Wolters Kluwer: Lippincott Williams \& Wilkins, 2010)15701597.

[2] Hagrod GA, Choudhary MT, Hussain A, Dynamic hip screw in proximal femur, Indian journal of orthopaedics, 28(2),1994, 3-6.

[3] Atul S, Srivastava KP, Anupam G, Treatment of trochanteric fracture by dynamic hip screw \& gamma locking nail, Indian journal of orthopaedics,31(2), 1997,118-22.

[4] Wee-Yoo.Kim, Chang-Hwan Han, Jin II Park, Failure of Intertrochanteric fracture fixation with dynamic hip screw in relation to postoperative fracture stability and osteoporosis, International Orthopaedics, 25, 2001, 360-62.

[5] Evans EM, Tochantericc fractures, J Bone Joint Surgery, 33(B), 1951, 192-204.

[6] Ali Sedighi, Jafar Ganjpour Sales, Sahar Alavi, The prognostic value of tip apex distance in intertrochanteric fractures fixed by dynamic hip screw, Orthopedic Reviews,4(32),2012,143-45.

[7] Cleveland M, Bosworth M, Thompson FR, Intertrochanteric fracture of femur, a survey of treatment in traction and by internal fixation, J Bone Joint surgery, 29, 1947, 1049-67.

[8] Baumgaertner MR, Curtin SL, Lindskog DM, Intramedullary versus extramedullary fixation for the treatment of intertrochanteric hip fractures, Clin Orthop, 348, 1998, 87-94.

[9] Lavelle DG, Fractures and dislocations of hip, in Canale TS, Beaty JH (1 $1^{\text {th }}$ Ed), Camphbell's Operative Orthopaedics, (Mosby: Elsevier 2007) Part 15.

[10] Baixauli F, Vincent V, Baixauli E, Rigid fixation device for unstable intertrochnateric fractures, Clin orthop, 361, 1999, $201-15$.

[11] Agrawala S, Kohli S, A short barallel dynamic hip screw for treatment of intertochanteric fracture in indian population, Indian journal orthop,40(4), 2007, 235-37. 